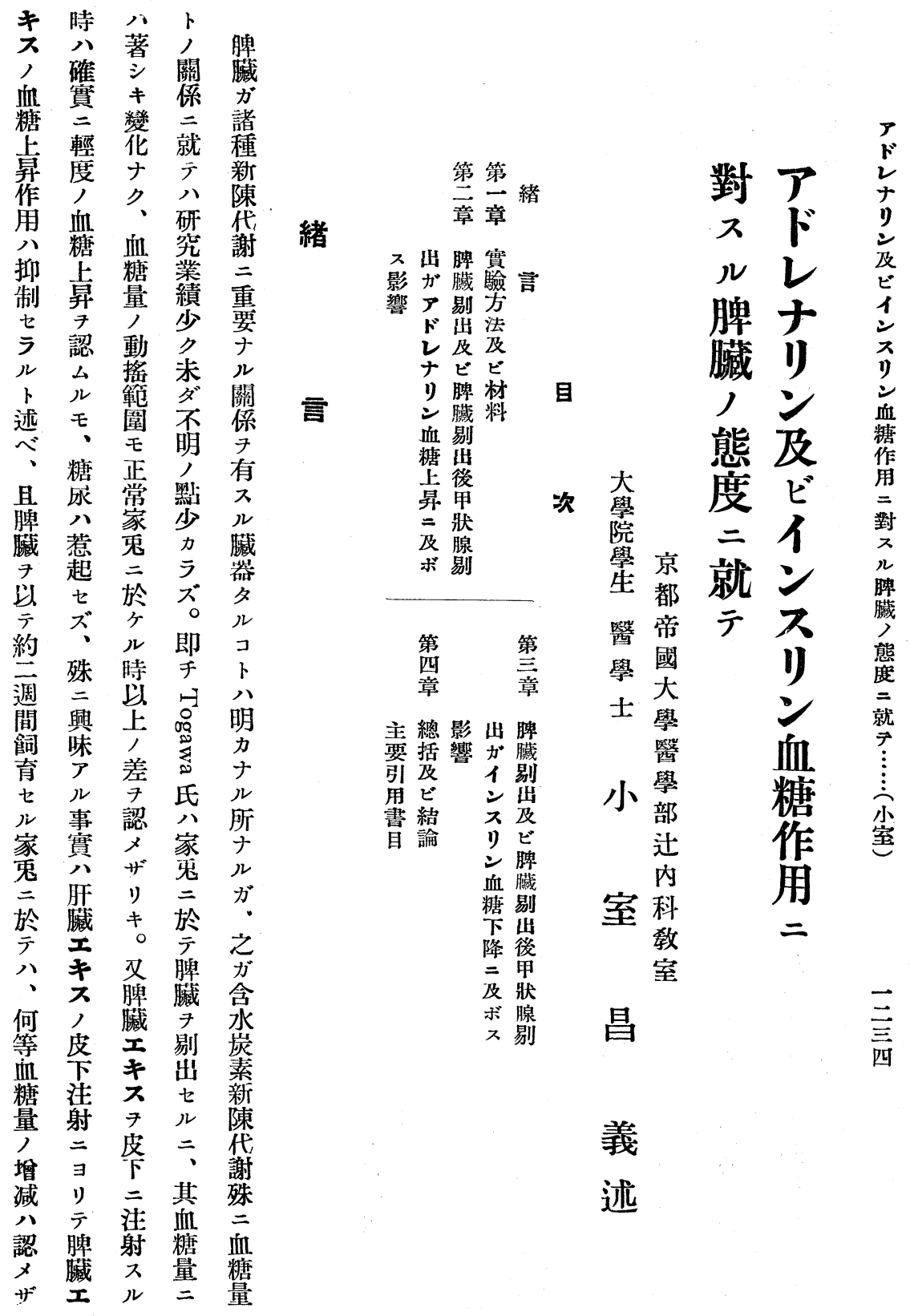




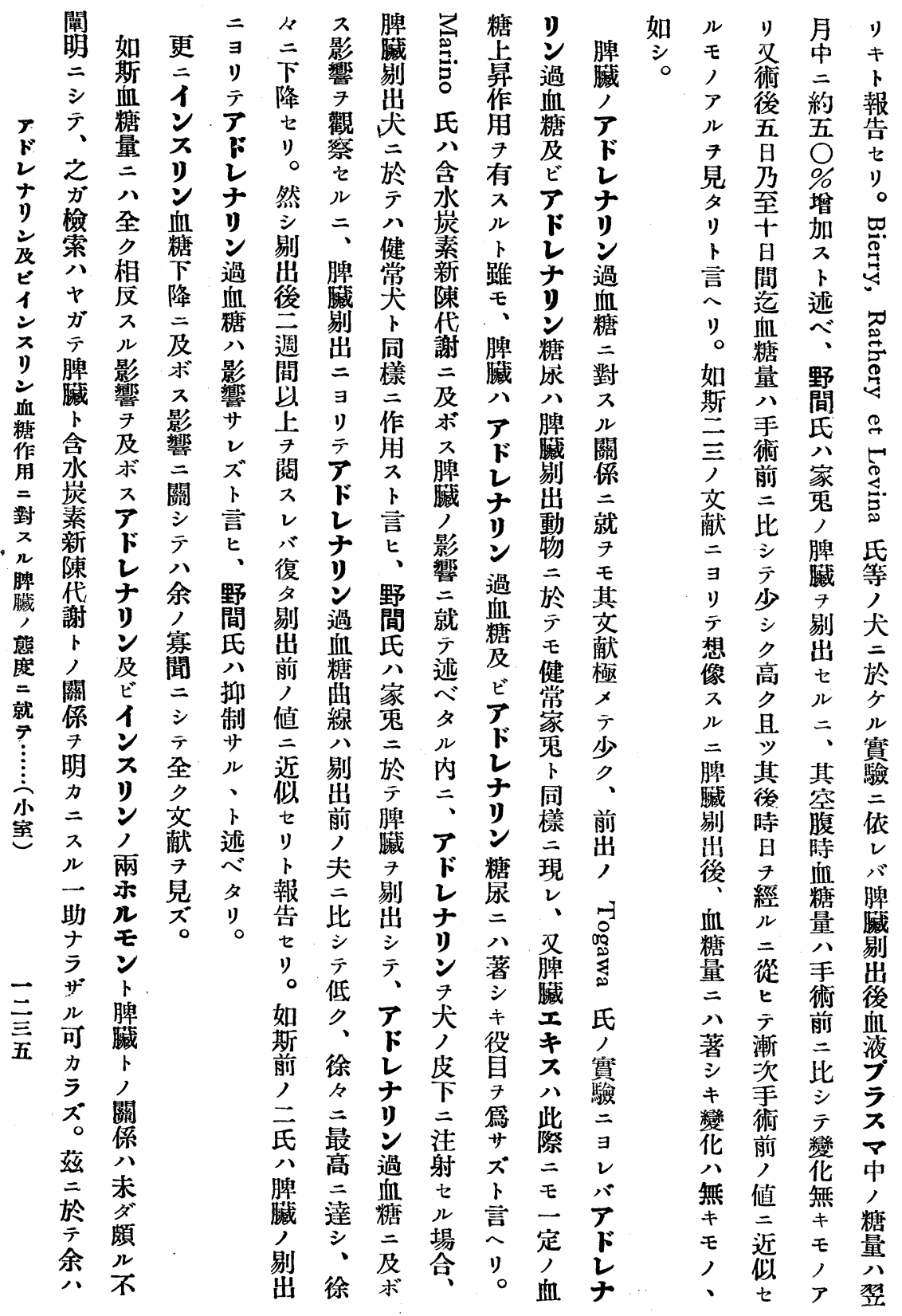




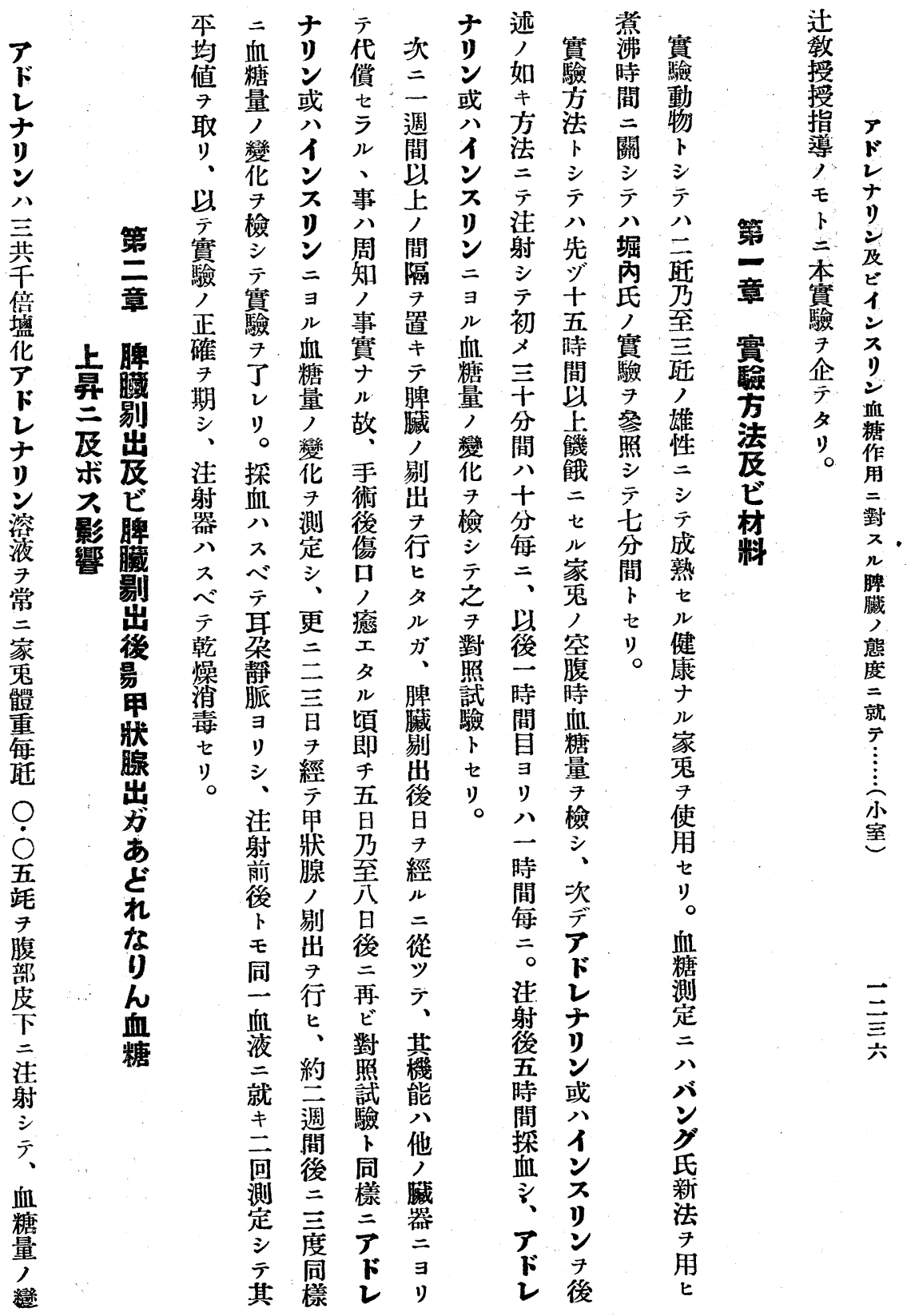




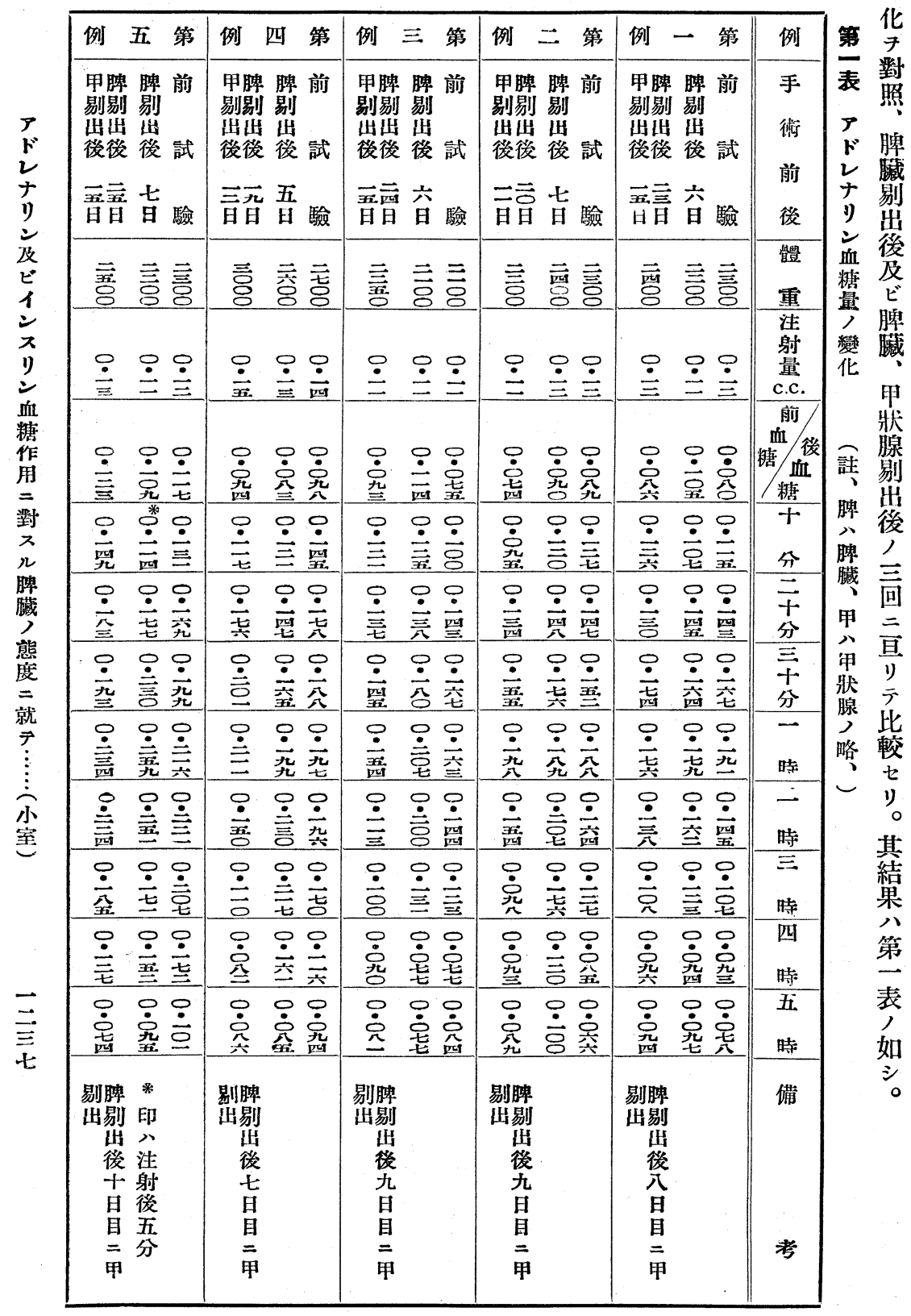




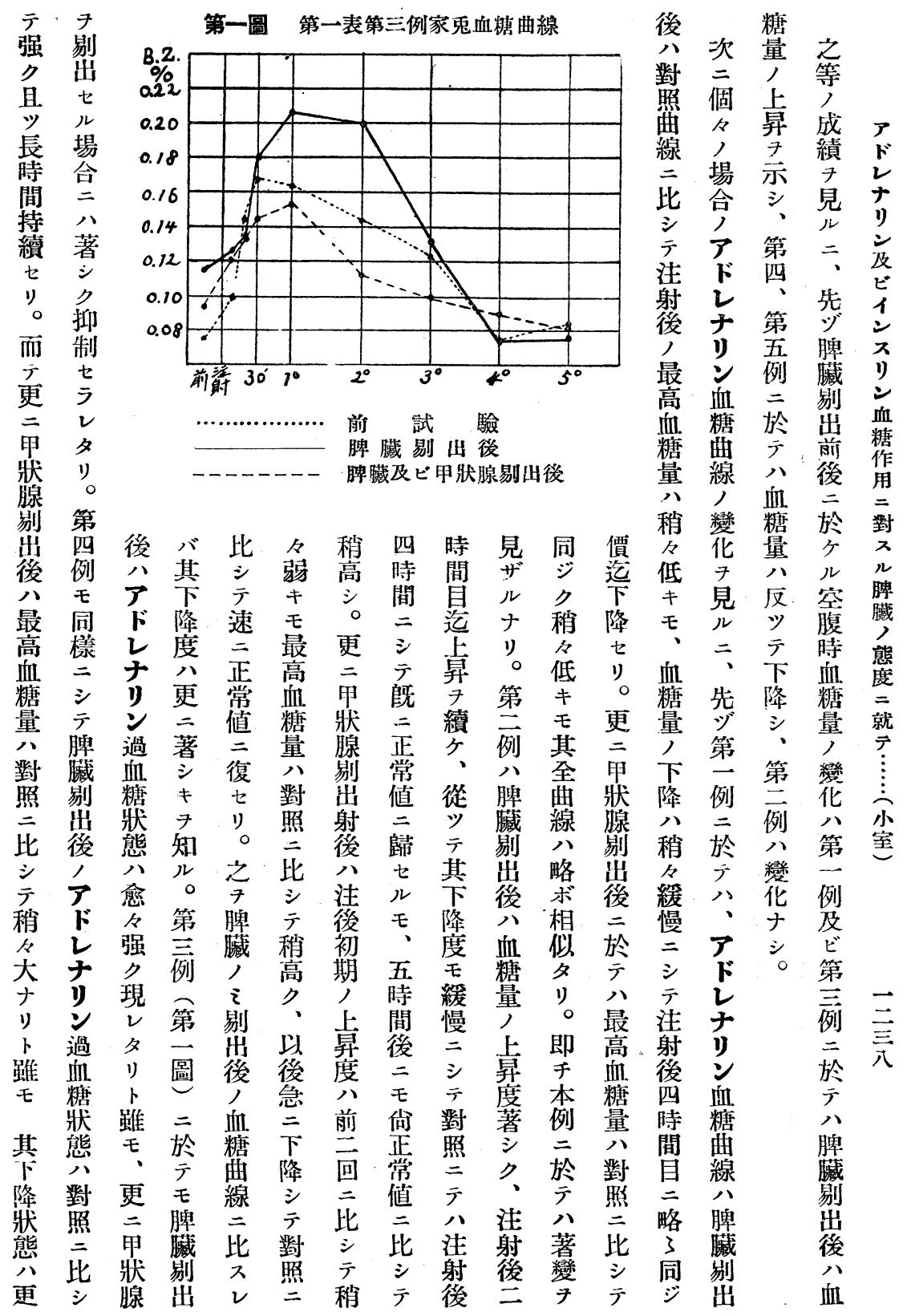




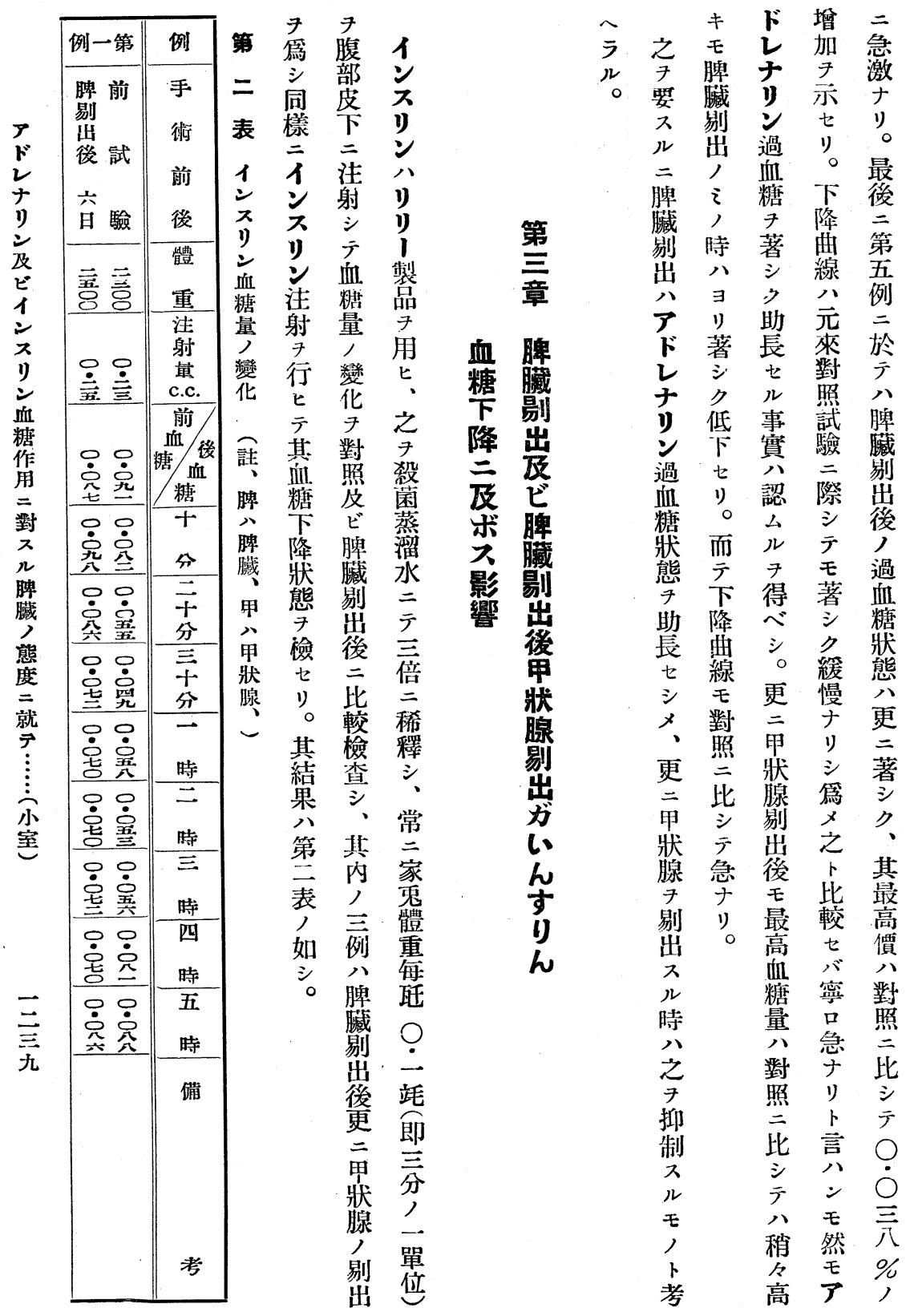




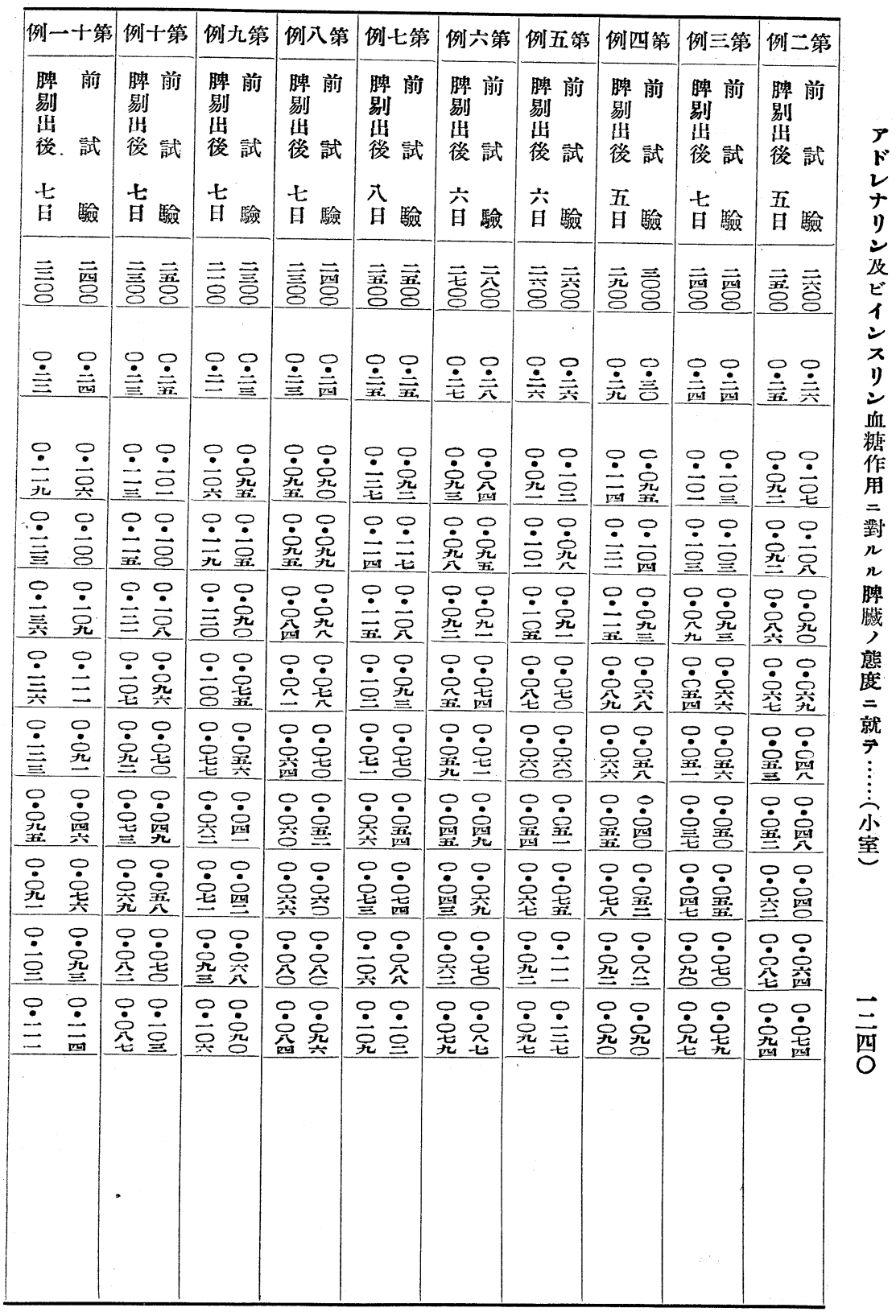




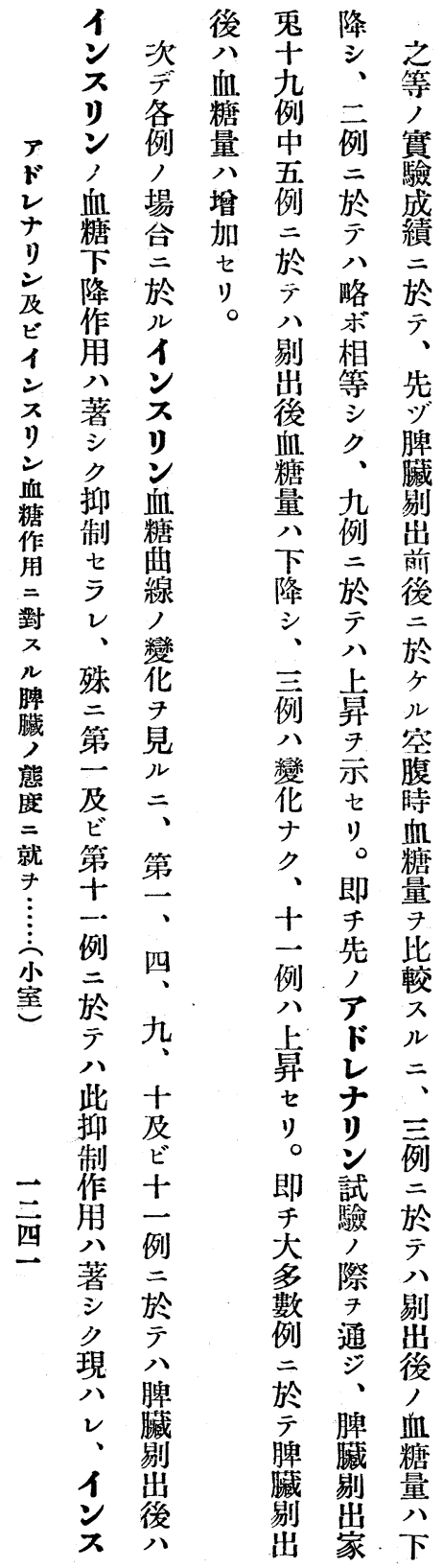

\begin{tabular}{|c|c|c|c|}
\hline 例四十第 & 例三十第 & 例二十第 & 例 \\
\hline $\begin{array}{l}\text { 甲脾 脾 前 } \\
\text { 剔剔 剔 } \\
\text { 出出 } \\
\text { 後後 後 試 }\end{array}$ & $\begin{array}{l}\text { 甲脾脾前 } \\
\text { 剔剔剔 } \\
\text { 岃出出 } \\
\text { 後後後試 }\end{array}$ & $\begin{array}{l}\text { 甲脾 脾 前 } \\
\text { 剔剔 剔 } \\
\text { 出出 } \\
\text { 後後 後 試 }\end{array}$ & $\begin{array}{l}\text { 手 } \\
\text { 術 } \\
\text { 前 }\end{array}$ \\
\hline 䆩言音 & 百言旨 & 害香公 & 後 \\
\hline 完 咅完 & 言 穵 $\overline{8}$ & 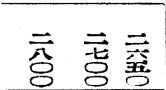 & $\begin{array}{l}\text { 體 } \\
\text { 重 }\end{array}$ \\
\hline 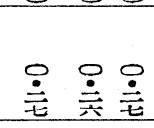 & 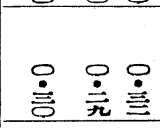 & 䒺妾竎 & $\begin{array}{l}\text { 注 } \\
\text { 射 } \\
\text { 量 } \\
\text { c.c. }\end{array}$ \\
\hline 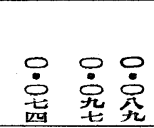 & 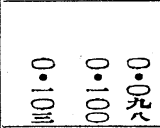 & 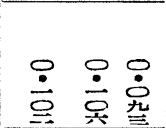 & 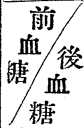 \\
\hline 宽兰完 & 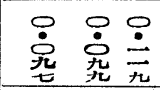 & 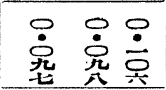 & + \\
\hline 家 & 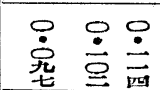 & 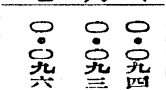 & 章 \\
\hline 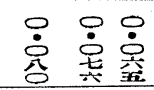 & 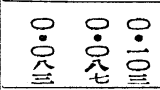 & 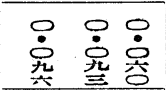 & $\begin{array}{l}\equiv \\
\text { 竞 }\end{array}$ \\
\hline 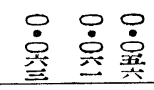 & 虽宾富 & 웅ㅇㅎㅇ영 & 一 \\
\hline $\begin{array}{l}\dot{0} \\
\text { 息 } \\
\end{array}$ & 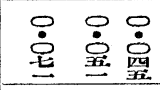 & 完 突芜 & $\begin{array}{l} \\
\text { 時 }\end{array}$ \\
\hline 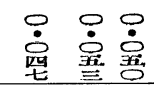 & 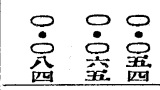 & 울 完宾 & 三 \\
\hline 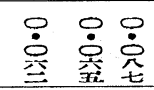 & 号 总完 & 웅 & 四 \\
\hline $\begin{array}{l}\text { 웅 } \\
\text { 突 } \\
\end{array}$ & 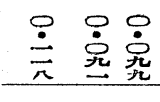 & 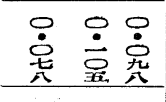 & $\begin{array}{l}\text { 五 } \\
\text { 時 }\end{array}$ \\
\hline $\begin{array}{c}\text { 剔脾 } \\
\text { 出剔 } \\
\text { 谈 } \\
\text { 炎 } \\
\text { 昌 } \\
\text { 旦 } \\
= \\
\text { 甲 }\end{array}$ & 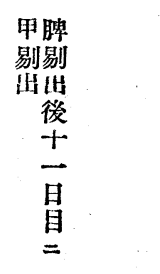 & $\begin{array}{c}\text { 甲脾 } \\
\text { 剔剔 } \\
\text { 出後 } \\
\text { 淩 } \\
\pm \\
\text { 昌 } \\
\stackrel{1}{=}\end{array}$ & 考 \\
\hline
\end{tabular}



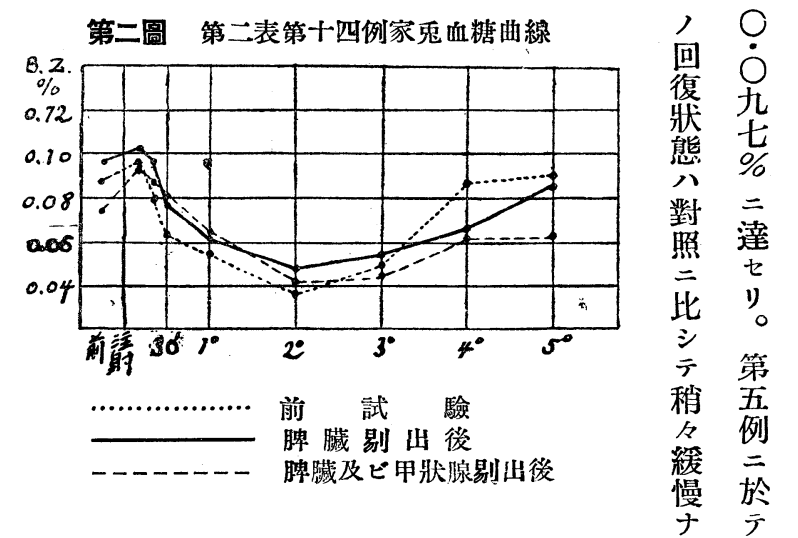

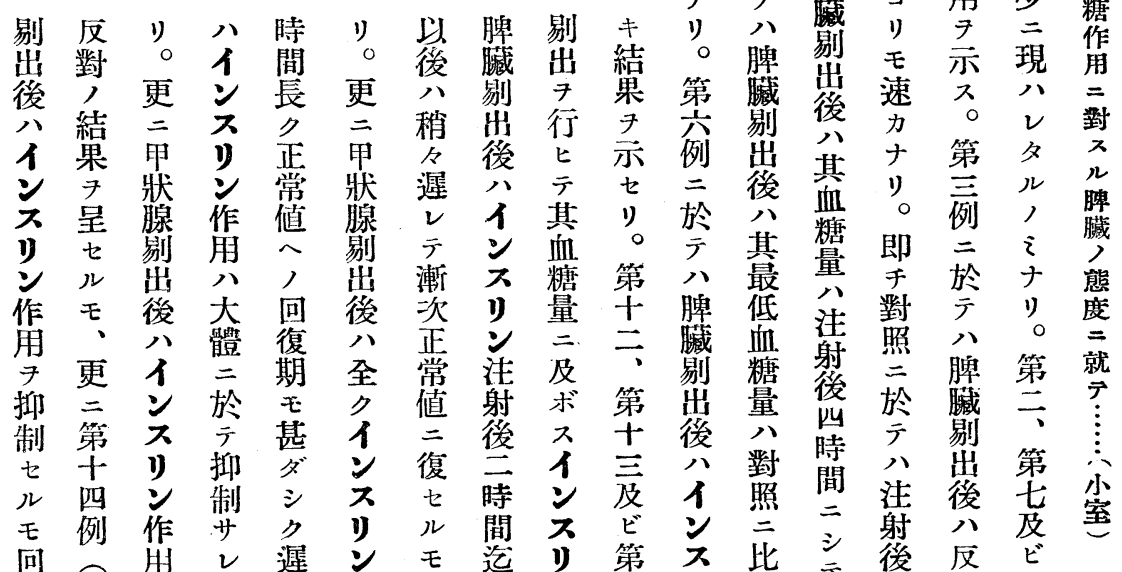

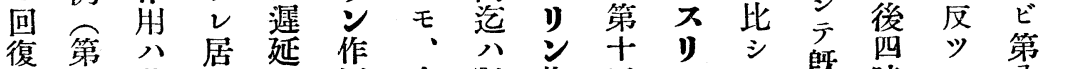

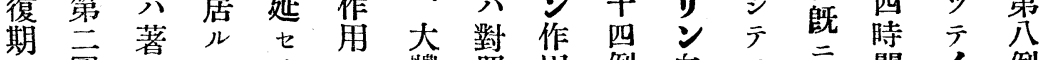

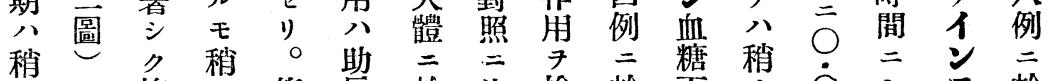

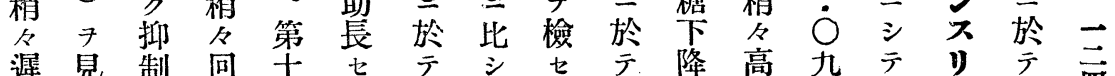

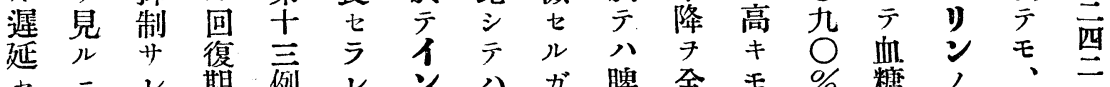

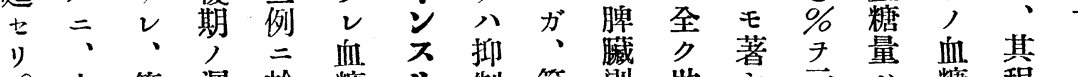

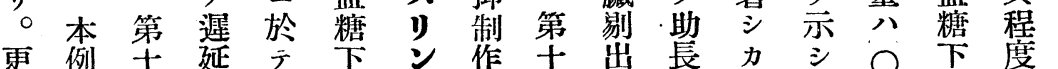

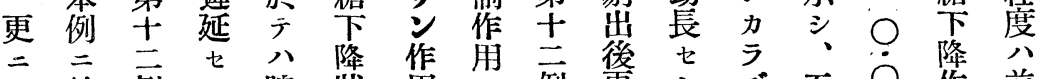

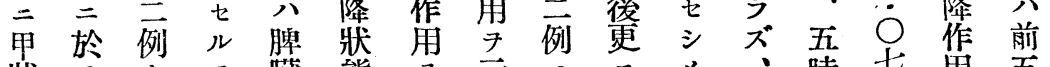

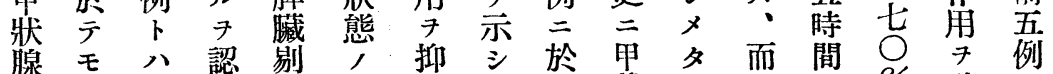

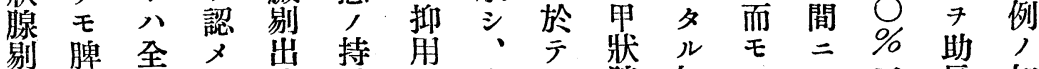

出藏》乡後續七夫八腺如り八五長如 


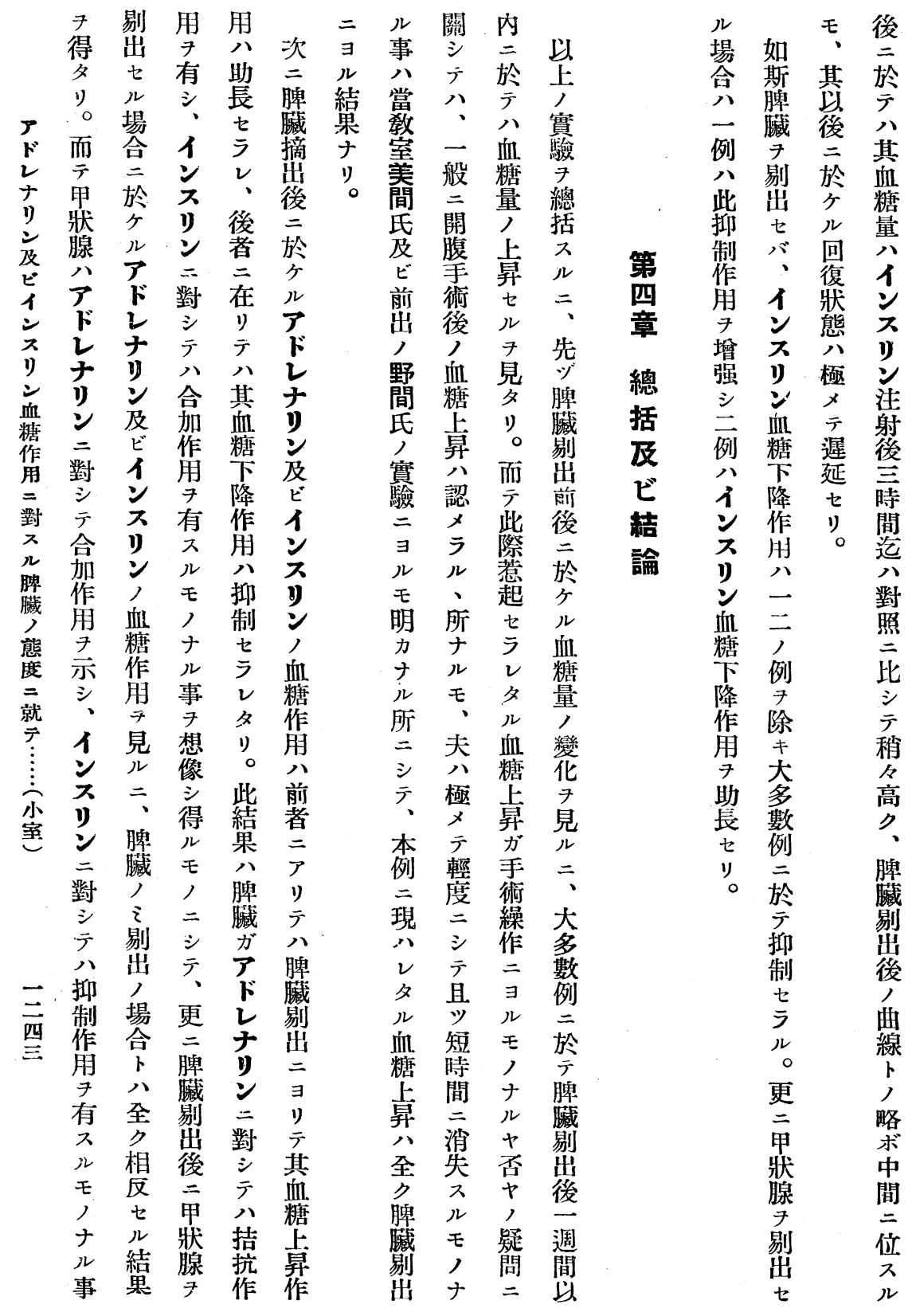




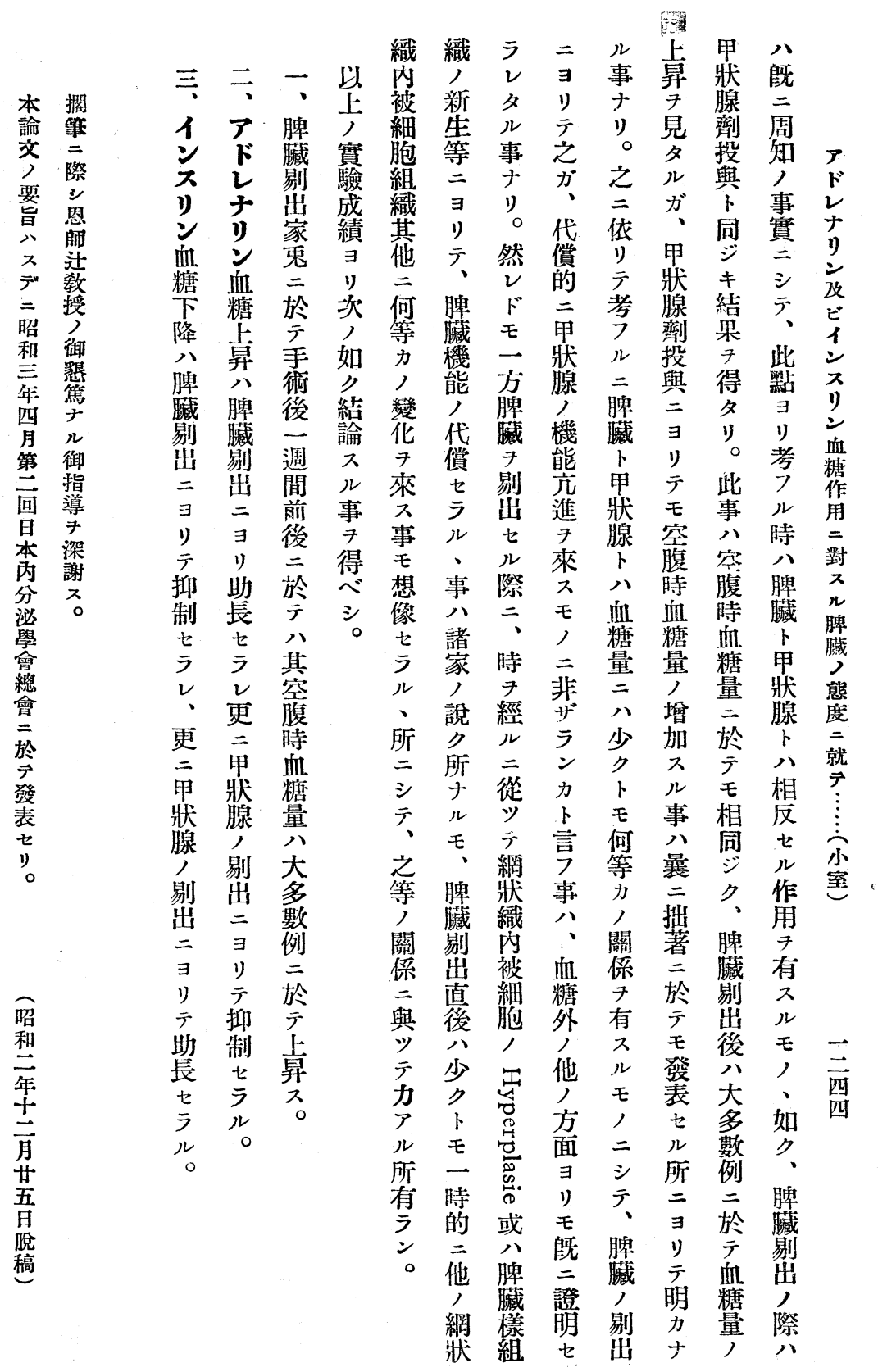


Pferdserums und bei Serumanaphylaxie.

2) Die mit Gemüse ernährten Kaninchen des gleichen Wurfes sind gegen Adrenalin unempfindlich, gegen Insulin dagegen empfindlich. Die mit Hafer ernährten Kaninchen sind gegen Adrenalin empfindlich, gegen Insulin dagegen unempfindlich. Doch ist dies nicht stets der Fall.

3) Bei den Kaninchen, die durch Gemüsenahrung vagotonisch geworden sind, zeigt sich nach Insulininjektion stärkere initiale Hyperglykämie.

4) Aus den obenerwähnten Resultaten ist ersichtlich, dass die initiale Hyperglykämie nach der Insulininjektion auftreten kann, wenn die Konstitution durch irgend eine Ursache verändert wird und es dadurch zu Vagotonie kommt.

5) Die initiale Hyperglykämie nach der Insulininjektion tritt stark hervor, wenn es im Tiere zu Vagotonie gekommen ist, gleichgültig auf welche Weise man das bewerkstelligt hat.

(Autoreferat)

\title{
Ueber die Stellung der Milz zum Adrenalin- und Insulinblutzuckerspiegel.
}

\author{
Von
}

Dr. M. Komuro.

(Aus der I. med. Klinik der Kaiserl. Univ. zu Kyoto in Japan. Direktor : Prof. Dr. K. Tsuji.)

Der Verfasser studierte die Beziehung zwischen der Milz und den zwei Hormonen, Adrenalin und Insulin, die den Blutzuckerspiegel antagonistisch beeinflussen.

Als Versuchstiere wurden Kaninchen gebraucht und als Methode der Blutzuckerbestimmung das neue Bangsche Verfahren.

Die Resultate waren die folgenden:-

I) Bei den milzlosen Kaninchen stieg der Blutzuckerwert 
des nüchternen Tieres in vielen Fällen eine Woche nach der Operation an.

2) Die Adrenalinhyperglykämie wurde nach der Milzexstirpation verstärkt und durch die spätere Schilddrüsenexstirpation gehemmt.

3) Die Insulinhypoglykämie wurde nach der Milzexstirpation gehemmt und durch die spätere Schilddrüsenexstirpation verstärkt.

(Autoref erat)

\section{Experimentelle Untersuchung über die Funktion des Epithelkörperchen. (I Mitteilung). (Epithelkörperchen und Durchlässigkeit des Magen-Darmkanals für heterogene Eiweiss.)}

Von

Dr. Piung-Hun Ri.

(Aus der chirur. Klinik d. Kaiserl. Universität zu Keijo.

Vorstand: Prof. Dr. Shigeshi Ogawa.)

I) Wenn man dem erwachsenen Kaninchen per os ziemlich grosse Menge von Eiereiweiss gibt, so sieht man, dass es durch die Schleimhaut des Magens in den Kreislauf kaum übergehen kann, aber dass es durch die Schleimhaut des Darmes in geringer Menge in den allgemeinen Kreislauf resorbiert wird. Von Darmschleimhaut resorbiertes Eiereiweiss wirkt als Antigen und lässt ziemlich starke Immunisierung des Versuchstiers erzielen.

Bei Parathyreoidektomiertem Kaninchen geht das per os gegebene Eiereiweiss reichlich durch die Schleimhaut des Magens und des Darmes in den allgemeinen Kreislauf über, aber bei diesem Kaninchen, trotz der reichlichen Resorption des Antigens, ist die Erzielung der starke Immunisierung unmöglich. 